\title{
STUDI PENGETAHUAN TENTANG MENSTRUASI DENGAN UPAYA PENANGANAN DISMENORE PADA MAHASISWA PENDIDIKAN BIOLOGI
}

\author{
Kusmiyati, I Wayan Merta, Syamsul Bahri \\ Program Studi Pendidikan Biologi Universitas Mataram \\ Email: Kusmiyati.fkip@unram.ac.id
}

\begin{abstract}
Abstrak. Dismenore merupakan keadaan nyeri pada waktu menstruasi yang dialami oleh perempuan. Nyeri ada yang berat tetapi ada juga yang ringan, pengetahuan tentang gangguan menstruasi akan menentukan penanganan dismenore yang di alaminya. Tujuan dari penelitian ini adalah untuk mengetahui hubungan pengetahuan tentang menstruasi dengan upaya penanganan dismenore. Populasi dalam penelitian ini adalah seluruh mahasiswa S1 Pendidikan Biologi semester 6 yang sedang mengambil matakuliah Anatomi Fisiologi Manusia, sedangkan sampel diambil secara purposive sampling, dengan kriteria mahasiswa perempuan yang mengalami dismenore. Data pengetahuan tentang menstruasi dikumpulkan dengan tes tertutup berupa tes pilihan ganda, sedangkan data upaya penanganan dismenore dikumpulkan menggunakan kuesioner. Selanjutnya hubungan pengetahuan menstruasi dengan upaya penanganan dismenore dianalisis dengan product moment. Hasil penelitian menunjukkan bahwa mahasiswa dengan pengetahuan tentang menstruasi baik sebanyak 72,7 \%, pengetahuan cukup sebanyak 27,3 \% dan berpengetahuan kurang $0 \%$. Upaya penanganan dismenore yang dipilih mahasiswa bervariasi, mahasiswa yang memilih cara farmakologi dan non farmakologi sekaligus sebanyak 2 orang $(6,06 \%)$, cara non farmakologi saja sebanyak 31 orang $(93,94 \%)$. Hasil uji korelasi product moment diperoleh $r$ hitung $=0,014<r$ tabel 0,05:33=0,344, berarti tidak ada hubungan pengetahuan mahasiswa tentang menstruasi dengan upaya penanganan dismenore. Kesimpulan penelitian ini adalah: a) Pengetahuan mahasiswa Pendidikan Biologi tentang menstruasi sebagian besar dalam kategori baik, b) Upaya penanganan dismenore pada mahasiswa Pendidikan Biologi sebagian besar dengan cara non farmakologi; c). Pengetahuan mahasiswa Pendidikan Biologi tentang menstruasi tidak menentukan upaya penanganan dismenore
\end{abstract}

Kata kunci: menstruasi, dismenore, mahasiswa, biologi

Abstract. Dysmenorrhea is a condition of pain during menstruation experienced by women. There are heavy and light of menstruation pain, knowledge of menstruation disorder will determine of the dysmenorrhea holding efforts. The purpose of this study was to determine the relationship of knowledge about menstruation and dysmenorrhea holding efforts. The population of this study was all students of Biology Education 6th semester who are taking the course of Human Anatomy and Physiology, while samples were taken by purposive sampling, with the criteria of female students who experience dysmenorrhea. Data of knowledge about menstruation collected by a multiple choice test, whereas the holding of dysmenorrhea collected using questionnaires. Furthermore, the relationship of knowledge of menstruation and the holding of dysmenorrhea was analyzed by Product Moment. The results showed that the students with good knowledge of menstruation were $72.7 \%$, insufficient knowledge were $27.3 \%$ and less knowledge were $0 \%$. Dysmenorrhea treatment efforts are chosen by the students are varied, students who choose to pharmacological and nonpharmacological simultaneously is $2(6.06 \%)$, non-pharmacological means only 31 people ( $93.94 \%)$. Product moment correlation test results obtained $r_{\text {count }}=0.014<r_{\text {table }} 0.05: 33=0.344$, meaning there is no relationship between student knowledge about menstruation and preventing dysmenorrhea. The conclusion of this study are : a) the student's knowledge about menstruation mostly categorized as good , b ) The handling of dysmenorrhea by students mostly by way of non-pharmacological; c ). Student knowledge about menstruation does not specify the handling of dysmenorrhea

Keywords: menstruation, dysmenorrhea, student, biology

\section{PENDAHULUAN}

Masa remaja merupakan tahapan antara masa kanak-kanak dengan masa dewasa, masa dari awal pubertas sampai tercapainya kematangan yang menurut [1] adalah masa diantara 12-21 tahun. Pertumbuhan dan perkembangan pada masa remaja sangat pesat, baik fisik maupun psikologis. Masa pubertas pada perempuan ditandai dengan perubahan fisik yang khas yaitu pematangan system reproduksi, salah satunya sudah mengalami menstruasi dan pada laki-laki sudah mampu menghasilkan sperma.

Kesehatan reproduksi adalah keadaan sejahtera baik fisik, mental, moral, sosial yang utuh dalam segala hal yang berkaitan dengan fungsi, peran dari sistem reproduksi wanita. Pengetahuan reproduksi sebaiknya 
dilakukan sejak remaja, karena seseorang akan dapat mengenali kelainan pada kesehatan reproduksinya sedini mungkin, terutama tentang menstruasi

Menstruasi adalah perubahan fisiologis pada wanita yang terjadi secara berkala dan dipengaruhi oleh hormon reproduksi, biasanya terjadi setiap bulan antara remaja sampai menopause. Menstruasi merupakan pelepasan dinding uterus yang disertai dengan pendarahan dan terjadi berulang setiap bulan, kecuali pada saat kehamilan Pada saat menstruasi biasanya wanita mengalami nyeri perut, yang biasa disebut dengan dismenore. Dismenore adalah kekakuan atau kejang di bagian bawah perut yang terjadi pada waktu menjelang atau selama menstruasi, yang memaksa wanita untuk beristirahat atau berakibat pada menurunnya kinerja dan berkurangnya aktivitas seharihari.

Angka kejadian dismenore di dunia sangat besar. Rata-rata lebih dari $50 \%$ perempuan di setiap negara mengalami dismenore. Di Indonesia kejadian dismenore diperkirakan sekitar 55\% perempuan produktif yang tersiksa oleh dismenore. Kejadian dismenore berkisar 45-95 \% di kalangan wanita usia produktif [2-4]

Subyek penelitian ini adalah mahasiswa S1 Pendidikan Biologi tahun ajaran 2014/2015 yang sedang mengambil matakuliah Anatomi Fisiologi Manusia, alasan mengambil mahasiswa tersebut karena sebagian besar pesertanya perempuan. Berdasarkan data awal yang diambil pada tanggal 15 Maret 2015, didapatkan jumlah keseluruhan mahasiswa sebanyak 71 orang yang terdiri dari 16 laki-laki dan 55 orang perempuan, yang sebagian besar mengalami nyeri haid pada waktu menstruasi.

\section{METODE PENELITIAN}

Populasi dalam penelitian ini adalah seluruh mahasiswa S1 Pendidikan Biologi semester 6 yang sedang mengambil matakuliah Anatomi Fisiologi Manusia, sedangkan sampel diambil secara purposive sampling, dengan kriteria mahasiswa perempuan yang mengalami dismenore. Data pengetahuan tentang menstruasi dikumpulkan dengan tes tertutup berupa tes pilihan ganda, sedangkan data upaya penanganan dismenore dikumpulkan menggunakan kuesioner. Data pengetahuan diolah secara kualitatif menjadi 3 kategori yaitu baik,cukup dan kurang, sedangkan data upaya penanganan dismenore menjadi farmakologi, non farmakologi dan tidak ditangani, kemudian dari masing-masing kategori dapat dihitung frekuensinya. Selanjutnya hubungan pengetahuan menstruasi dengan upaya penanganan dismenore dianalisis dengan Product Moment.

\section{HASIL PENELITIAN}

Hasil penelitian pengetahuan mahasiswa Pendidikan Biologi tentang menstruasi menunjukkan bahwa dari 33 mahasiswa yang mengalami haid, sebagian besar berpengetahuan baik dan tidak ada mahasiswa yang berpengetahuan kurang (Tabel 1)

Tabel 1 Pengetahuan Mahasiswa Tentang Menstruasi

\begin{tabular}{clcc}
\hline No & Tingkat pengetahuan & Jumlah & $\%$ \\
\hline 1 & Baik & 24 & 72,7 \\
2 & Cukup & 9 & 27,3 \\
3 & Kurang & 0 & 0 \\
& Jumlah & 33 & \\
\hline
\end{tabular}

Hasil penelitian upaya penanganan dismenore pada mahasiswa Pendidikan Biologi, menunjukkan bahwa dari 33 mahasiswa yang mengalami nyeri haid semua berupaya menangani nyerinya, yang sebagian besar dari mereka dengan menggunakan cara non farmakologi, sedang yang 2 mahasiswa menangani nyeri dengan cara farmakologi (minum obat dokter) dan non farmakologi (Tabel 2)

Tabel 2. Upaya Penanganan Dismenore

\begin{tabular}{clccc}
\hline No & \multicolumn{2}{l}{ Upaya penanganan dismenore } & Jumlah & $\%$ \\
\hline 1 & Farmakologi \& non & 2 & 6,06 \\
& farmakologi & & & \\
2 & Non farmakologi & & 31 & 93,94 \\
3 & Tidak ditangani & & 0 & 0 \\
& Jumlah & 33 & \\
\hline
\end{tabular}

Hasil penghitungan analisis hubungan dengan product moment menunjukkan bahwa $\mathrm{r}$ hitung $=0,014$ $<\mathrm{r}$ tabel 0,05:33 =0,344, ini berarti bahwa kedua variabel tidak berhubungan artinya pengetahuan yang dimiliki mahasiswa tidak menentukan upaya penanganan nyeri haidnya. Tabulasi silang hubungan pengetahuan tentang menstruasi dengan penanganan dismenore terangkum pada Tabel 3

Tabel 3. Tabulasi Silang Pengetahuan Dengan Upaya Penanganan Dismenore

\begin{tabular}{lcccc}
\hline \multirow{2}{*}{$\begin{array}{c}\text { Upaya } \\
\text { penanganan }\end{array}$} & \multicolumn{4}{c}{ Pengetahuan } \\
\cline { 2 - 5 } & Baik & Cukup & Kurang & Jumlah \\
\hline Farmakologi dan & 2 & 0 & 0 & 2 \\
non farmakologi & & & & \\
Non farmakologi & 22 & 9 & 0 & 31 \\
Tidak ditangani & 0 & 0 & 0 & 0 \\
Jumlah & 24 & 9 & 0 & 33 \\
\hline
\end{tabular}

\section{PEMBAHASAN}


Berdasarkan hasil pada Tabel 1 didapatkan bahwa sebagian besar mahasiswa mempunyai pengetahuan yang baik $(72,7 \%)$ tentang menstruasi, hal ini dapat dipahami karena mahasiswa sedang mengambil matakuliah Anatomi Fisiologi Manusia, yang salah satu materinya membahas tentang sistem reproduksi. Selain itu, mahasiswa dapat memperoleh informasi tentang menstruasi dari buku dan media massa seperti Televisi, majalah, internet dan sebagainya. Sesuai dengan pendapat [5], pengetahuan adalah segala apa yang diketahui, yang merupakan hasil tahu, setelah seseorang melakukan pengindraan dengan penglihatan, pendengaran, penciuman, perasa dan peraba. Sebagian pengetahuan diperoleh melalui penglihatan dan pendengaran. Lebih lanjut dijelaskan tingkat pengetahuan yang paling rendah adalah tahu, yang diartikan mengingat suatu materi yang telah dipelajari sebelumnya. Termasuk mengingat kembali sesuatu yang spesifik dari seluruh bahan yang dipelajari atau rangsangan yang telah diterima.

Berdasarkan Tabel 2 didapatkan bahwa sebagian besar mahasiswa $(93,94 \%)$ menangani nyeri ketika haid dengan cara non farmakologi (tidak meminum obat), yang sebagian besar menggunakan lebih dari satu macam cara. Hal ini dapat dipahami karena rasa nyeri bersifat individual, sehingga cara mana yang dipilih untuk mengurangi nyeri sangat tergantung dari kenyamanan masing-masing individu. Apabila cara satu dirasa kurang nyaman, maka dipilih lagi cara yang lain. Seperti data yang diperoleh pada penelitian ini, ada mahasiswa yang sudah memilih penanganan dengan diolesi minyak kayu putih tetapi juga dengan kompres hangat, nafas dalam dan perut di pijat. Mahasiswa yang lain memilih menggunakan cara perut di pijat, dan menggunakan stagen, ada pula yang memilih perut dipijat dan tidur dengan perut diganjal bantal. Ditemukan 2 mahasiswa yang memilih baik cara farmakologi (dengan meminum obat dari dokter) dan non farmakalogi (di pijat).

Pemilihan upaya penanganan dismenore (nyeri haid) lebih disebabkan kebiasaan masing-masing individu dan tingkat kenyamanan yang mereka rasakan. Seperti pendapat [6], yang menyatakan bahwa nyeri merupakan mekanisme fisiologis yang bertujuan untuk melindungi diri. Apabila seseorang merasakan nyeri, maka perilakunya akan berubah. Tamsuri [7], menyebutkan reseptor nyeri (nosiseptor) adalah organ tubuh yang berfungsi untuk menerima rangsang nyeri, Organ tubuh yang berperan sebagai reseptor nyeri adalah ujung saraf bebas dalam kulit yang berespons hanya terhadap stimulus kuat yang secara potensial merusak. Lebih lanjut dijelaskan berdasarkan letaknya, nosiseptor dikelompokkan dalam beberapa bagian tubuh yaitu kulit, somatic dalam dan daerah visceral., karena letaknya yang berbeda-beda, maka nyeri yang timbul juga memiliki sensasi yang berbeda, Asmadi [8] menambahkan, nyeri merupakan sensasi yang rumit, unik, universal dan bersifat individual, karena respon individu terhadap sensasi nyeri beragam dan tidak disamakan satu dengan lainnya.

Berdasarkan analisis hubungan kedua variabel menggunakan product moment diperoleh hasil $\mathrm{r}$ hit = $0,014<\mathrm{r}$ tabel 0,05:33=0.344, yang berarti tidak ada hubungan pengetahuan tentang menstruasi dengan upaya penanganan dismenore. Ini berarti bahwa tidak bisa dikatakan seseorang yang berpengetahuan baik akan menangani nyeri haidnnya dengan baik pula. Seperti yang terlihat pada tabulasi silang (Tabel 3), bahwa mahasiswa yang berpengetahuan cukup juga memilih cara penanganan non farmakologi, sehingga kata "baik" pada cara penanganan nyeri dalam penelitian ini berarti bahwa seseorang telah berusaha menangani nyerinya dengan caranya sendiri sesuai dengan kenyamanan yang dirasakan.

Berdasarkan hasil penelitian upaya penanganan yang dipilih mahasiswa dapat dikelompokkan menjadi 5 macam cara yaitu kompres, stimulasi kontralateral, pijat/massage, distraksi dan relaksasi. Cara yang paling banyak dipilih mahasiswa adalah pijat, pijat merupakan pemberian tekanan pada berbagai titik organ tubuh, yang menimbulkan sensasi nyaman, termasuk dalam kelompok pijat adalah menggunakan stagen, dan pinggang di ganjal bantal. Pijatan akan membantu memperlancar sirkulasi darah yang terganggu dan meningkatkan kenyamanan, sehingga mengurangi rangsangan nyeri. Pijatan mengurangi ketegangan otot dan stress tubuh secara keseluruhan, dengan tujuan utama agar tubuh dan pikiran rileks. Relaksasi nafas dalam juga banyak dipilih mahasiswa, relaksasi juga menurunkan nyeri dengan merelaksasikan ketegangan otot yang mendukung rasa nyeri.

Kompres hangat pada prinsipnya menyebabkan vasodilatasi sehingga dapat meningkatkan aliran darah ke bagian tubuh yang mengalami cidera dan menurunkan ketegangan otot, sehingga meningkatkan relaksasi otot dan mengurangi nyeri. Seperti pendapat [6], stimulasi panas dapat menimbulkan respon fisiologis yang berbeda efek terapeutik pemberian kompres adalah: a) permeabilitas kapiler meningkat; b). vasodilatasi (meningkatkan aliran darah); c). viskositas darah menurun; d) ketegangan otot menurun; e) metabolism jaringan meningkat.

Apapun pilihan upaya penanganan dismenore yang dipakai mahasiswa, semuanya bertujuan untuk mengurangi nyeri (dismenore) atau meningkatkan kenyamanan, kenyamanan diperoleh karena aliran darah lancar dan ketegangan otot menurun, sehingga tidak bisa dikatakan bahwa yang memilih cara di pijat lebih baik dibanding cara yang lain, atau yang meminum obat lebih baik daripada yang tidak meminum obat. Sesuai pendapat [9], dismenore yang terjadi pada remaja disebabkan oleh proses menstruasi 
itu sendiri yang merangsang otot-otot rahim untuk berkontraksi. Kontraksi otot rahim tersebut membuat aliran darah menjadi berkurang yang berakibat meningkatnya aktivitas rahim untuk memenuhi kebutuhannya akan aliran darah yang lancar, otot yang kekurangan darah tadi akan merangsang ujung saraf, sehingga terasa nyeri.

Upaya penanganan dismenore yang dilakukan mahasiswa juga ada dengan destraksi yaitu pengalihan terhadap nyeri yang dirasakan, cara yang dipilih adalah dengan tiduran, melakukan aktivitas, tidur serta ditahan. Nyeri yang muncul tidak dirasakan atau diabaikan, dengan fokus ke stimulus yang lain, sehingga impuls nyeri tidak sampai ke otak. Seperti pendapat [7], distraksi adalah pengalihan dari focus perhatian terhadap nyeri ke stimulus yang lain. Teknik distraksi dapat mengatasi nyeri berdasarkan teori bahwa aktivasi retikuler menghambat stimulus nyeri, jika seseorang menerima input sensori yang berlebihan dapat menyebabkan terhambatnya impuls nyeri ke otak.

Potter \& Perry [6] menyatakan, secara hormonal terjadinya dismenore (nyeri haid) disebabkan oleh peningkatan kadar prostaglandin di dalam darah yang merangsang peningkatan kontraksi dan disritmik uterus, sehingga terjadi penurunan aliran darah dan oksigen ke uterus yang mengakibatkan iskemia. Munculnya respon dari reseptor disebabkan adanya stimulus yang membahayakan dan memulai transmisi neural dengan melepaskan substansi yang menghasilkan nyeri. Lebih lanjut dijelaskan, sensasi nyeri terjadi ketika merasakan nyeri, individu bereaksi terhadap nyeri dengan cara yang berbeda.

Beberapa upaya penanganan nyeri yang dipilih mahasiswa seperti tersebut di atas, ditujukan untuk mengatasi nyeri dengan merangsang tubuh melepaskan senyawa yang dapat menciptakan perasaan nyaman dan tenang. Seperti pendapat [10], pemijatan akan meningkatkan aliran darah, yang pada gilirannya akan memeras pembuluh kapiler dan kelenjar getah bening serta membuang racun dari tubuh. Tubuh akan memberikan respon untuk meningkatkan aliran darah dengan memproduksi lebih banyak sel darah merah yang membawa oksigen ke otot, memberikan rasa nyaman dan mendorong pikiran untuk memproduksi endorphin yang merupakan penghilang rasa sakit yang alami bagi tubuh.

\section{KESIMPULAN}

Berdasarkan hasil dan pembahasan dapat disimpulkan:

1. Pengetahuan mahasiswa Pendidikan Biologi tentang menstruasi sebagian besar dalam kategori baik
2. Upaya penanganan dismenore pada mahasiswa Pendidikan Biologi sebagian besar dengan cara non farmakologi

3. Pengetahuan mahasiswa Pendidikan Biologi tentang menstruasi tidak menentukan upaya penanganan dismenore

\section{DAFTAR PUSTAKA}

[1]. Sumiati, 2009, Kesehatan jiwa Remaja dan Konseling, TIM, Jakarta

[2]. Proverawati, A. dan Maisaroh, S. 2009, Menarche, Menstruasi Pertama Penuh Makna, Nuha Medika, Yogyakarta

[3]. Sumawati, S. (2010). Hubungan antara pengetahuan dengan sikap mahasiswi keperawatan si dalam mengatasi dismenore di fakultas ilmu kesehatan Universitas Muhammadiyah Surakarta, Disertasi Program Doktor, Universitas Muhammadiyah Surakarta.

[4]. Prajati, R. N. (2015). Hubungan Pengetahuan Kesehatan Reproduksi Remaja Putri dengan Sikap Menghadapi Premenstrual Syndrome di SMP Mataram Kasihan Tahun 2014 Disertasi Program Doktor, STIKES'Aisyiyah Yogyakarta.

[5]. Notoadmodjo, 2010, Metode penelitian Kesehatan, Rineka Cipta, Jakarta

[6]. Potter \&Perry, 2005, Fundamental Keperawatan,EGC, Jakarta

[7]. Tamsuri, A. 2006, Konsep dan Penatalaksanaan Nyeri, EGC, Jakarta

[8]. Asmadi, 2009, Teknik Prosedural Keperawatan: Konsep dan Kebutuhan dasar Klien, Salemba Medika, Jakarta

[9]. Novia, I., \& Puspitasari, N. (2008). Faktor Risiko yang Mempengaruhi Kejadian Dismenore Primer. The Indonesian Journal of Public Health, 4(2), 96-104.

[10]. Rowen, 2007, Pemijatan, Karisma Publishing Group, Tangerang 